\title{
A INFLUÊNCIA DO PRIMING GRAFO-FÔNICO-FONOLÓGICO EM UMA TAREFA DE DECISÃO LEXICAL EM MULTILÍNGUES FALANTES DE PORTUGUÊS (L1), INGLÊS (L2) E FRANCÊS (L3)
}

\author{
THE INFLUENCE OF GRAPHO-PHONIC-PHONOLOGICAL PRIMING ON A LEXICAL \\ DECISION TASK ON MULTILINGUALS SPEAKERS OF PORTUGUESE (L1), ENGLISH \\ (L2) AND FRENCH (L3)
}

\author{
Aline Behling Duarte ${ }^{4}$ \\ Cíntia Ávila Blank ${ }^{5}$
}

\begin{abstract}
RESUMO: Este artigo discute a influência do priming grafo-fônico-fonológico na execução de uma tarefa de decisão lexical realizada por multilíngues. Nesse sentido, buscou-se verificar se semelhanças grafo-fônico-fonológicas entre palavras das línguas estudadas (português, inglês e francês) influenciariam o tempo de reação na tarefa. Com o auxílio do software E-Prime 2.0, foi elaborado um experimento que contou com 90 pares de palavras, das quais metade apresentava supostas semelhanças grafo-fônico-fonológicas entre si, enquanto a outra metade não apresentava tais similaridades. Considerando a Hipótese de Seleção Não-Específica (CONKLIN; MAUNER, 2005), defendeu-se que as supostas semelhanças grafo-fônico-fonológicas entre as línguas promoveriam a ativação de correspondências grafofônico-fonológicas distintas, acarretando uma maior competição lexical entre os itens investigados, evidenciada no aumento dos tempos de reação (MACWHINNEY, 2005). Os resultados encontrados indicaram que os tempos de reação foram maiores para os itens que apresentavam as semelhanças grafo-fônico-fonológicas entre prime e palavraalvo, o que parece apontar para uma possível influência dos níveis de proficiência em cada uma das línguas dos participantes nesses resultados.
\end{abstract}

Palavras-chave: Acesso lexical; priming; influência grafo-fônico-fonológica; multilinguismo; níveis de proficiência.

\begin{abstract}
This article discusses the influence of grapho-phonic-phonological priming on the execution of a lexical decision task performed by multilinguals. In this sense, we tried to verify if grapho-phonic-phonological similarities between words of the studied languages (Portuguese, English and French) would influence the reaction time in the task. With the aid of the E-Prime 2.0 software, an experiment was carried out with 90 pairs of words, half of which had supposed grapho-phonic-phonological similarities to each other, while the other half had no similarities. Considering the Non-Specific Selection Hypothesis (CONKLIN; MAUNER, 2005), it was argued that the supposed grapho-phonic-phonological similarities between languages would promote the activation of distinct grapho-phonicphonological correspondences, leading to greater lexical competition between the two investigated items, evidenced by the increase in reaction times (MACWHINNEY, 2005). The results indicated that the reaction times were longer for the items that presented the graphical-phonological similarities between prime and target word, which seems to point to a possible influence of proficiency levels in each of the participants languages results.

Keywords: Lexical access; priming; grapho-phonic-phonological influence; multilingualism; levels of proficiency.
\end{abstract}

\section{Introdução}

No campo de pesquisa da aquisição e da aprendizagem de línguas, o fenômeno referente ao conhecimento de três ou mais línguas parece não receber a mesma atenção dedicada ao conhecimento de duas línguas. Apesar do aumento do número de multilíngues, ainda são escassos os trabalhos voltados à pesquisa das influências translinguísticas em falantes multilíngues, especialmente no Brasil. Entre os poucos estudos feitos no país, podem ser citados os esforços

\footnotetext{
4 Doutoranda do Programa de Pós-Graduação em Letras da Universidade Federal de Pelotas-UFPel.

5 Doutora em Letras/Linguística Aplicada pela Universidade Católica de Pelotas-UCPel. Professora Adjunta da Universidade Federal de Pelotas-UFPel e do Programa de Pós-Graduação em Letras da mesma instituição. Coordenadora do Curso de Letras-Espanhol a Distância da UFPel.
} 
desenvolvidos por Blank (2008, 2013), Brito (2011), Toassi e Mota (2015), Barcelos (2016), Pickbrenner (2017), Limberger (2018) e Duarte (2018).

À luz de uma perspectiva Psicolinguística, este trabalho apresenta um estudo sobre o acesso lexical em falantes de Português (L1), Inglês (L2) e Francês (L3), de forma a contribuir com os estudos voltados ao multilinguismo e à metodologia de priming. Acredita-se que o tópico discutido seja pertinente em função das diversas combinações entre línguas que podem ser pesquisadas no contexto nacional, em especial quando se investigam as influências dos padrões grafo-fônicofonológicos entre as línguas. A partir do estudo apresentado, busca-se expandir os estudos sobre o acesso lexical voltado ao multilinguismo, fenômeno pouco estudado se comparado às pesquisas desenvolvidas com falantes bilíngues. Além disso, procura-se colaborar com a ampliação do entendimento de como se dá o processamento da linguagem em multilíngues através do estudo acerca do acesso lexical.

Valer-se dos benefícios que a Psicolinguística pode fornecer aos professores de línguas estrangeiras é de essencial importância para a comunidade docente. Entender como os processos mentais ocorrem possibilita ampliar o conhecimento acerca do processamento da linguagem e, portanto, proporciona a capacidade de modificar a maneira de ensinar. Nesse sentido, a transformação da sala de aula impulsiona o avanço científico, de forma a incentivar o próprio professor a buscar respostas para inquietações que surgem de suas novas práticas docentes. Pesquisas relacionadas ao acesso lexical - especialmente em multilinguismo - são de suma importância para o aperfeiçoamento de professores. Acredita-se que com o aprofundamento teórico proporcionado pelos resultados de estudos sobre a temática, o entendimento de por qual razão os aprendizes têm dificuldades em lembrar ou armazenar novas palavras na língua estrangeira pode ser mais bem esclarecido. Por conseguinte, as práticas de sala de aula podem ser reconsideradas, sendo mantidas, remodeladas ou substituídas por ações que serão mais proveitosas para alunos e professores. À vista disso, considera-se que uma das contribuições mais importantes para o âmbito docente está relacionada a desbancar a concepção de que as transferências que ocorrem entre línguas são passíveis de serem impedidas e que devem ser evitadas a qualquer custo durante o processo de aprendizagem.

Para o desenvolvimento deste trabalho, foram adotados os seguintes aportes teóricosmetodológicos, a saber: priming (HERMANS et al., 1998; LEMHÖFER et al., 2004; BUSNELLO, 2006; FRANÇA et al, 2008; BLANK; ZIMMER, 2010), níveis de proficiência, Hipótese de Seleção Não-Específica (CONKLIN; MAUNER, 2005) e Modelo de Competição (MACWHINNEY, 2005). Na próxima seção, são apresentadas as definições para os conceitos que fundamentam esta pesquisa. Em seguida, o método utilizado é apresentado. Na seção seguinte, a discussão e os resultados obtidos no trabalho são explanados. Por fim, é feito o encerramento do artigo, ao listarse as conclusões observadas.

\section{Fundamentação Teórica}

O conceito de priming pode ser definido como um fenômeno cognitivo que ocorre quando um estímulo prévio, chamando de prime, facilita ou dificulta o processamento de uma informação, o alvo (BUSNELLO, 2006). França et al. (2005) explicam que um estímulo pode ser acessado mais rapidamente se precedido, em curto prazo, por outro estímulo com o qual compartilhe alguma propriedade. No caso de palavras, a literatura aponta o efeito facilitador que um estímulo causa sobre outro, geralmente quando ambos compartilham conteúdo semântico (FRANÇA et al., 2008).

Rodriguez-Fornells et al. (2005) explicam que palavras cognatas costumam causar um efeito facilitador em experimentos lexicais, uma vez que esses tipos de palavras compartilham informações tanto semânticas quanto relacionadas à forma. Por outro lado, palavras consideradas homógrafas entre línguas dificilmente são diferenciadas em relação à forma, mas apresentam 
A influência do priming grafo-fônico-fonológico em uma tarefa de decisão lexical em multilíngues falantes de português (L1), inglês (L2) e francês (L3) | 15

significados extremamente diferentes. Nesse sentido, partindo-se da ideia de que o processamento linguístico ocorre em paralelo, será necessário um grande controle cognitivo para acessar uma palavra-alvo, dependendo do contexto linguístico da tarefa. Ainda de acordo com RodriguezFornells et al. (2005), vários estudos defendem que a ativação em paralelo de duas línguas pode levar a uma facilitação quando participantes devem decidir se uma palavra existe, independente de identificar em que língua está essa palavra. Contudo, efeitos de interferência podem surgir se a tarefa do participante for realizar uma decisão lexical a respeito de uma das línguas, de forma específica.

Em tarefas que envolvem a metodologia de priming, espera-se que o participante apresente algum tipo de resposta com relação ao alvo. A utilização do efeito de priming em investigações sobre como acontece o acesso lexical em bilíngues e multilíngues originou uma série de trabalhos que advogam pela Hipótese de Seleção Não-Específica (HSNE) das línguas (HERMANS et al., 1998; LEMHÖFER et al., 2004; BLANK; ZIMMER, 2010). Isso implica assumir que a ativação lexical flui livremente entre as representações, fazendo com que múltiplos nós lexicais, em mais de uma língua, sejam ativados ao mesmo tempo, sendo necessário, então, um mecanismo de seleção lexical.

Nesta pesquisa, defende-se a ideia de que as línguas e o acesso ao léxico são não-seletivos. Seguindo-se essa lógica, concorda-se com os estudos realizados com palavras cognatas, em que se comprova o efeito de facilitação que a ativação de múltiplas línguas pode gerar. Todavia, acreditase que os resultados de pesquisas realizadas com palavras homógrafas, que atestam uma maior dificuldade no acesso e escolha de um item lexical, não contradizem a hipótese de acesso nãoseletivo. Nesse sentido, argumenta-se que, como palavras cognatas entre línguas apresentam uma congruência entre forma e significado, essas palavras são identificadas com maior rapidez, uma vez que não há informação discordante entre os itens e, geralmente, as tarefas realizadas apenas demandam que os participantes identifiquem se o item lexical alvo é ou não uma palavra. Com isso, a atenção dos participantes está centrada em identificar palavras, não importando em que língua elas se apresentam. $O$ fato de não haver informação discordante entre os itens lexicais apenas ajuda na execução rápida da tarefa. Por outro lado, quando palavras homógrafas são utilizadas, o próprio fato de haver um acesso não-seletivo às línguas e ao léxico faz com que haja uma maior dificuldade em identificar e acessar a palavra-alvo, devido às ambiguidades relacionadas à correspondência grafo-fônico-fonológica entre as línguas e ao conteúdo semântico. Parece, então, haver uma dificuldade em separar a ativação das línguas, e a incongruência entre grafemos e fonemas juntamente com a diferença semântica entre itens pode acabar dificultando a pronta resposta dos participantes às tarefas solicitadas. (RODRIGUEZ-FORNELLS et al., 2005; BLANK, 2013).

Levando essas questões em consideração, buscou-se averiguar, através de uma tarefa de decisão lexical com priming, se a transferência de padrões grafo-fônico-fonológicos pode influenciar o acesso lexical. $O$ trabalho trata-se de um estudo em que multilíngues falantes de português (L1), inglês (L2) e francês (L3) foram submetidos a um experimento no qual deveriam identificar a qual língua pertencia o estímulo oferecido na tela de um computador. Analisou-se o papel da grafia sobre a ativação fonético-fonológica, por meio de combinações feitas entre as três línguas que fazem parte deste estudo. Foram estipuladas duas condições de priming: o priming grafo-fônicofonológico relacionado (PGFFR) e o priming grafo-fônico-fonológico não relacionado (PGFFNR). O primeiro tipo de prime consiste em pares de palavras que são relacionadas na forma ortográfica e na forma fonético-fonológica, como, por exemplo, "mass" ("missa" em língua inglesa) e "mas" (conjunção da língua portuguesa). O segundo tipo de prime vale-se de pares de palavras que não apresentam nenhuma semelhança na forma ortográfica e na forma fonético-fonológica, como, por exemplo, "arte" (substantivo da língua portuguesa) e "ilha” (substantivo da língua portuguesa). Espera-se obter resultados similares aos apresentados por Hermans et al. (1998), Lemhöfer et al. 
(2004), e Blank e Zimmer (2010) quando esses autores estipulam que o prime que apresenta supostas semelhanças com seu alvo, sem compartilhar conteúdo semântico, demanda maior tempo de reação (TR) na identificação dos itens lexicais, já que ativa correspondentes de todas as línguas faladas pelos participantes, causando, assim, uma maior demora na indicação de resposta. No contexto deste artigo, ressalta-se que não se buscou observar o efeito semântico no acesso lexical, mas o efeito de pistas supostamente semelhantes através das correspondências grafo-fônicofonológicas, que tendem a prejudicar a pronta ativação, provocando uma competição entre os candidatos a léxico.

Em relação ao processamento da linguagem em falantes bilíngues, Conklin e Mauner (2005) esclarecem que não há consenso entre pesquisadores de como as línguas são acessadas. A divergência gira em torno da ativação das representações lexicais. Uma das posições defendidas é a Hipótese de Seleção Específica (HSE), em que a ativação acontece de forma a apenas ativar uma das línguas, ou seja, apenas os itens lexicais da língua de resposta são ativados. Os itens lexicais da língua que não está em uso estariam "adormecidos". Já a posição da Hipótese de Seleção NãoEspecífica (HSNE) argumenta que a ativação ocorre nos itens lexicais de todas as línguas faladas pelos indivíduos. Conforme a HSNE, quando um bilíngue em inglês-francês escuta ou lê a palavra coin (em inglês - moeda e em francês - canto), serão ativados os léxicos de ambas as línguas, com seus respectivos conteúdos semânticos. A visão de competição proposta por MacWhinney (2005) corrobora os postulados defendidos na HSNE, quando sugere que pistas grafo-fônico-fonológicas, por exemplo, não ativam apenas um único item lexical na língua alvo, mas também ativam itens lexicais de todas as línguas faladas pelos indivíduos.

O Modelo de Competição Unificado (MCU) proposto por MacWhinney (2005) parte do argumento de que é mais sensato considerar apenas um modelo de aprendizagem tanto para a L1 e a L2 quanto para aquisição multilíngue, já que se parte da premissa de que o processamento lexical em todos os casos se dá da mesma forma. Nesse sentido, espera-se que, durante o processamento, ocorram disputas de seleção entre os itens lexicais. Para o autor, itens linguísticos competem entre si por ativação, em virtude de sua força relativa. Entende-se, então, que o item lexical que obtiver o maior número de ativações, ou seja, que mais frequentemente for utilizado/acessado por um indivíduo, será favorecido ao competir com um outro item menos ativado. $\mathrm{O}$ item ganhador é considerado mais forte e terá vantagem sobre o mais fraco. Nesta pesquisa, acredita-se que os itens lexicais das línguas de maior proficiência serão ativados de maneira mais forte do que os itens lexicais das línguas de menor proficiência. Assim, quando um prime com semelhanças grafo-fônicofonológicas for apresentado em uma língua cujos participantes possuem maior nível de proficiência, espera-se que o tempo de reação (TR) computado para atribuir resposta à palavra-alvo seja significativamente maior, comparado a situações em que o prime seja apresentado em língua em que os participantes tenham menos proficiência. Após a apresentação do aporte teórico basilar deste trabalho, são apresentados o método empregado para a seleção dos participantes, a coleta e a análise dos dados.

\section{Método}

Este estudo foi conduzido com dados provenientes de 18 informantes, discentes da Universidade Federal de Pelotas (UFPel), que se dispuseram a assinar um Termo de Consentimento Livre e Esclarecido (TCLE). Todos os participantes satisfizeram os pré-requisitos estabelecidos na pesquisa, a saber: ter o português como única L1; concordaram em fazer um teste de proficiência leitora avançada em inglês como L2; participar de um teste de proficiência leitora intermediária em francês como L3. Após serem entrevistados, os voluntários responderam a um questionário (BLANK, 2013) sobre suas experiências linguísticas e realizaram as provas de 
A influência do priming grafo-fônico-fonológico em uma tarefa de decisão lexical em multilíngues falantes de português (L1), inglês (L2) e francês (L3) | 17

nivelamento em leitura. Em seguida da correção dos testes de proficiência ${ }^{6}$, os sujeitos foram convidados a realizar o experimento de decisão lexical com priming grafo-fônico-fonológico.

Aplicou-se o experimento desenvolvido por Blank (2013), que consistiu em uma tarefa de identificação lexical, contendo 90 pares de palavras. Em cada estímulo, eram apresentadas duas palavras por escrito, o prime e a palavra-alvo, respectivamente. Para o experimento, foram projetadas duas condições de priming grafo-fônico-fonológico: priming grafo-fônico-fonológico relacionado (PGFFR) e priming grafo-fônico- fonológico não relacionado (PGFFNR). Na categoria PGFFR, os pares de estímulos apresentavam semelhanças grafêmicas e fonético-fonológicas, como é o caso para cara-CARO, por exemplo. $\mathrm{Na}$ condição PGFFNR, as palavras pareadas não apresentavam as mesmas similaridades, como, por exemplo, em rain-BANK. Salienta-se que tanto os pares de palavras com PGFFR quanto os pares com PGRRNR foram selecionados levando em consideração o fato de serem palavras de alta frequência, de possuírem o mesmo número de sílabas e de não manterem relação semântica aparente entre os pares de palavras.

Cada uma das duas condições contava com nove combinações, feitas entre as três línguas que faziam parte do estudo. Assim, foram obtidas as seguintes combinações tanto para o grupo de PGFFR quanto para o grupo de PGFFNR: português-PORTUGUÊS, português-INGLÊS, português-FRANCÊS, francês-FRANCÊS, francês-INGLÊS, francês-PORTUGUÊS, inglêsINGLÊS, inglês-FRANCÊS e inglês-PORTUGUÊS. A Tabela 01 ilustra as 18 possibilidades de apresentação. A Tabela 02 exemplifica os pares de palavras utilizados no experimento.

Tabela 01: Combinações entre as línguas

\begin{tabular}{|c|c|c|c|c|}
\hline \multirow[b]{2}{*}{ Combinação de línguas } & \multicolumn{4}{|c|}{ Condição } \\
\hline & Tipo de condição & $\begin{array}{l}\text { Número de } \\
\text { itens }\end{array}$ & Tipo de condição & $\begin{array}{l}\text { Número de } \\
\text { itens }\end{array}$ \\
\hline português-PORTUGUÊS & PGFFR & 5 & PGFFNR & 5 \\
\hline português-FRANCÊS & PGFFR & 5 & PGFFNR & 5 \\
\hline português-INGLÊS & PGFFR & 5 & PGFFNR & 5 \\
\hline francês-FRANCÊS & PGFFR & 5 & PGFFNR & 5 \\
\hline francês-INGLÊS & PGFFR & 5 & PGFFNR & 5 \\
\hline francês-PORTUGUÊS & PGFFR & 5 & PGFFNR & 5 \\
\hline inglês-INGLÊS & PGFFR & 5 & PGFFNR & 5 \\
\hline inglês-FRANCÊS & PGFFR & 5 & PGFFNR & 5 \\
\hline inglês-PORTUGUES & PGFFR & 5 & PGFFNR & 5 \\
\hline Total & & 45 & & 45 \\
\hline
\end{tabular}

Fonte: Elaborado pelas autoras

Tabela 02: Exemplificação dos pares de palavras utilizados

\begin{tabular}{c|c|c}
\hline Combinação de línguas & PGFFR & PGFFNR \\
\hline português-PORTUGUÊS & cem-SEI & dar-VOZ \\
\hline português-FRANCÊS & cor-CORPS & por-SUN \\
\hline português-INGLÊS & fim-FINE & cas-FEU \\
\hline francês-FRANCÊS & vent-VIN & soir-FAKE \\
\hline francês-INGLÊS & homme-HOME & façon-PROVA \\
\hline francês-PORTUGUÊS & lait-LEI & rain-BANK \\
\hline inglês-INGLÊS & two-TOO & desk-POCHE \\
\hline inglês-FRANCÊS & come-COMME & gold-LAR \\
\hline
\end{tabular}

Fonte: Elaborado pelas autoras

\footnotetext{
${ }^{6}$ Os participantes realizaram testes de leitura em língua inglesa e francesa, respectivamente TOEFL e DALF.
} 
A elaboração das listas de palavras foi feita levando em consideração os aspectos grafêmicos e fonético-fonológicos que deviam estar presentes nos pareamentos PGFFR. O experimento foi montado, utilizando pares cujos itens lexicais fossem monossilábicos ou dissilábicos, em função da dificuldade em listar 45 pares de palavras em que pudessem ser observados os mesmos números de sílabas e as similaridades necessárias para que houvesse a possibilidade de testagem. Para que não houvesse erros em virtude do desconhecimento dos vocábulos empregados, todas as palavras utilizadas são de alta frequência e foram extraídas de corpora ${ }^{7}$ da língua portuguesa, inglesa e francesa.

Ao realizarem a tarefa, os participantes recebiam dois estímulos: o prime e a palavra-alvo. $\mathrm{O}$ primeiro permanecia na tela do computador por 1000 milissegundos (ms), em caixa baixa. Em seguida, a palavra-alvo era apresentada em caixa alta na tela do notebook, pelo tempo necessário para que o participante identificasse a qual das três línguas o vocábulo pertencia. Após a atribuição de uma resposta, uma tela de transição com uma cruz no centro permanecia na tela do computador até que os participantes pressionassem alguma tecla para prosseguirem com o experimento. Os informantes foram instruídos a ignorar o primeiro estímulo e a focarem seus esforços em identificar o segundo, da forma mais rápida que pudessem. Foram instituídas que as teclas 1, 6 e 0 seriam utilizadas para computar as respostas, referindo-se respectivamente às línguas portuguesa, inglesa e francesa. Antes de iniciar o teste, os informantes foram submetidos a uma seção de prática, na qual se familiarizariam com a dinâmica do experimento e tinham a possibilidade de solucionar quaisquer dúvidas remanescentes. O experimento propriamente dito era iniciado apenas quando o sujeito indicasse não ter dúvidas sobre como proceder e, o mais importante, tivesse obtido escore de $100 \%$ de acertos na prática. A partir desse experimento, foi possível coletar dados como o TR dos participantes para responder aos estímulos.

Para a montagem do experimento e a coleta de dados, foi utilizado o software E-Prime 2.0 (Psychology Software Tools, Inc, 2012). A partir desta ferramenta, obteve-se o TR necessário para que cada palavra-alvo pudesse ser analisada. Com esse programa computacional, também foi possível verificar o número de acertos e erros cometidos por cada informante. A análise dos dados pôde ser feita através do programa estatístico SPSS 22.0 (IBM CORP., 2013). Após a rodagem do teste de normalidade, observou-se que os dados dividiam-se em normais e não-normais, acarretando no uso de testes estatísticos paramétricos e não-paramétricos. Para a análise estatística da amostra normal, com distribuição paramétrica, escolheu-se o Teste-T Pareado. Já para a amostra designada nãonormal, com distribuição não-paramétrica, optou-se pelo Teste de Wilcoxon, uma alternativa nãoparamétrica para o Teste-T pareado.

\section{Resultados e discussão}

A primeira hipótese feita no estudo indicava que os multilíngues exibiriam um TR significativamente maior para responder aos pares que apresentassem semelhanças grafo-fônicofonológicas entre si, como é o exemplo de county-CONTA (combinação entre inglês e português). De acordo com a visão não-seletiva aqui adotada, esperava-se que essas possíveis semelhanças de ordem grafo-fônico-fonológicas dificultariam o pronto acesso à língua a ser acessada, devido à maior competição entre os padrões grafo-fônico-fonológicos similares entre as três línguas. Nesse sentido, os padrões linguísticos das três línguas dos multilíngues estariam competindo no momento da escolha lexical, dificultando a realização da tarefa quando os pares de palavras apresentassem as semelhanças aqui analisadas.

\footnotetext{
${ }^{7}$ A elaboração da lista de primes e palavras-alvo foi feita através de três corpora: Ceten-Folha, para o português, Lexique, para o francês, e Brown, para o inglês.
} 
A partir da análise da Tabela 03, pode-se observar que o grupo de informantes demorou cerca de $8 \%$ a mais em tempo (ms) para identificar as palavras-alvo que eram precedidas pelo PGFFR, ou seja, que mantinham uma relação de similaridade grafo-fônico-fonológica. Notou-se que a média do TR dos participantes foi de 1034,68 ms na condição PGFFNR, enquanto que a média de TR dos informantes foi de 1119,13 ms na condição PGFFR. Apesar de esta comparação revelar uma diferença pequena, de apenas $84,45 \mathrm{~ms}$, constou-se estatisticamente a existência de diferenças significativas no teste $\mathrm{X}(\mathrm{Z}=-2,918, \mathrm{p}<0,05)$. No que se refere aos valores de desviopadrão, observou-se o aumento de $210,59 \mathrm{~ms}$ para 244,15 ms nas condições de PGFFNR e PGFFR, respectivamente.

Tabela 03: Comparação dos TR (ms) nas condições PGFFNR e PGFFR

\begin{tabular}{c|c|c|c|c}
\hline Tipo de itens lexicais & Média $(\mathrm{ms})$ & Desvio-Padrão & Valor de $Z$ & Valor de $\boldsymbol{p}$ \\
\hline PGFFNR & 1034,68 & 210,59 & $-2,918$ & 0,04 \\
\hline PGFFR & 1119,13 & 244,15 & \\
\hline \multicolumn{2}{|c|}{ Fonte: Elaborado pelas autoras }
\end{tabular}

A segunda hipótese delineada para o estudo previa que os níveis de proficiência dos multilíngues em cada uma das três línguas influenciariam os TR durante a tarefa de decisão lexical. As línguas nas quais os informantes possuíssem maior fluência e maior frequência de exposição, quando apresentadas na posição de prime, atrasariam os TR e afetariam a precisão com que os participantes atribuiriam resposta às palavras-alvo durante a tarefa de decisão lexical, conforme indica MacWhinney (2005). Partiu-se de uma abordagem de seleção não-específica entre as línguas (HERMANS et al., 1998; LEMHÖFER et al., 2004; BLANK; ZIMMER, 2010), que dispõe que os padrões grafo-fônico-fonológicos das línguas mais proficientes influenciam nos TR de forma determinante. Em outras palavras, seguindo-se a visão de Rodriguez-Fornells et al. (2005) este experimento utiliza palavras que podem ser consideradas homógrafas entre as línguas. Esse tipo de palavras, ao contrário das palavras cognatas, não compartilha do mesmo conteúdo semântico, causando certa dificuldade no acesso ao léxico, já que há maior competição entre os itens. Já as línguas em que os participantes possuem maior proficiência devem ser consideradas mais estabilizadas no sistema cognitivo dos participantes. $\mathrm{O}$ aumento de frequência de exposição a essas palavras, aliado ao fato de os participantes possuírem, teoricamente, um conhecimento lexical mais abrangente e possivelmente com mais conexões entre diferentes informações, acaba dificultando o acesso à resposta lexical demandada nas palavras-alvo. Neste caso, as palavras-alvo são apresentadas em língua que os participantes possuem menos proficiência, o que pode significar menos força de ativação durante a competição lexical quando a língua pré-ativada é muito mais proficiente, causando um efeito difícil de ser superado pela língua de menor proficiência na posição de alvo. No que se refere aos níveis de proficiência, partiu-se da perspectiva observada por Woutersen (1997 apud DE BOT, 2007, p. 43) de que, quanto maiores os níveis de proficiência em cada língua, menores seriam as influências de outras línguas durante a ativação lexical. Ao fragmentar os dados verificados nas combinações feitas entre português (L1), inglês (L2) e francês (L3), pode-se visualizar, em detalhes, quais foram os TR demandados para que a resposta fosse emitida na condição PGFFR. A Tabela 04 ilustra as médias de TR e a mediana (MD) em cada uma das 9 combinações. 
Tabela 04: Resultados para o TR (ms) na condição PGFFR

\begin{tabular}{c|c|c}
\hline Combinações PGFFR & Média $(\mathrm{ms})$ & Mediana $(\mathrm{ms})$ \\
\hline português - PORTUGUÊS & 1016,55 & 963,50 \\
\hline português - FRANCÊS & 1126,94 & 1074,50 \\
\hline português - INGLÊS & 1176,66 & 1082,00 \\
\hline francês - FRANCÊS & 1220,33 & 1183,50 \\
\hline francês - INGLÊS & 1089,72 & 1015,00 \\
\hline francês - PORTUGUÊS & 1011,55 & 1002,00 \\
\hline inglês - INGLÊS & 1198,55 & 1161,00 \\
\hline inglês - FRANCÊS & 1327,88 & 1198,00 \\
\hline inglês - PORTUGUÊS & 958,11 & 944,00 \\
\hline
\end{tabular}

Fonte: Elaborado pelas autoras

Ao levar em consideração os resultados obtidos em cada uma das 9 combinações, percebe-se que quando a palavra-alvo era apresentada em L1, as médias dos TR foram as menores. Destaca-se que a menor média de TR ocorreu na combinação inglês-PORTUGUÊS, na qual se constatou 958,11 ms $(\mathrm{MD}=944,00 \mathrm{~ms})$. Na combinação francês-PORTUGUÊS, notou-se um pequeno aumento no TR, tendo a média sido 1011,55 ms e $(\mathrm{MD}=1002,00 \mathrm{~ms})$. Na combinação portuguêsPORTUGUÊS, constatou-se a média de tempo 1016,55 ms (MD = 963,50 ms).

Um dos exemplos de maiores médias de TR apuradas aparecem nas condições que englobam as línguas estrangeiras: inglês-FRANCÊS e francês-INGLÊS. Em L2-L3, detectou-se o tempo de $1327,88 \mathrm{~ms}(\mathrm{MD}=1198,00 \mathrm{~ms})$. Na combinação entre L3-L2, verificou-se o TR de 1089,72 ms $(\mathrm{MD}=1015,00 \mathrm{~ms})$. Nas combinações em que as palavras-alvo eram apresentadas em línguas estrangeiras, observou-se que em português-FRANCÊS a média de TR foi 1126,94 ms (MD = 1074,50 ms). No arranjo português-INGLÊS, o TR foi 1176,66 ms (MD =1082,00 ms).

Nos arranjos nos quais ambos os primes e as palavras-alvo foram apresentados nas mesmas línguas estrangeiras, notaram-se valores de médias de TR ligeiramente mais altas do que nas demais combinações de línguas. Em francês-FRANCÊS evidenciou o TR médio de 1220,33 ms (MD = 1183,50 ms). Já em inglês-INGLÊS, a média dos TR computada foi 1198,55 ms (MD = 1161,00 $\mathrm{ms})$.

Com o intuito de chegar a uma conclusão a respeito dos dados coletados, foram feitas comparações entre os arranjos, nos quais o prime e a palavra-alvo pertencessem à mesma língua, como, por exemplo, em português-PORTUGUÊS vs. francês-FRANCÊS. Também foram feitas comparações entre as combinações que apresentavam o prime e a palavra-alvo em posições contrárias como, por exemplo, português-INGLÊS vs. inglês-PORTUGUÊS. Assim, seis comparações foram efetuadas, através do Teste-T pareado e do Teste de Wilcoxon: portuguêsPORTUGUES vs. francês-FRANCÊS, português-PORTUGUÊS vs. inglês-INGLÊS, francêsFRANCÊS vs. inglês-INGLÊS, português-FRANCÊS vs. francês-PORTUGUÊS, portuguêsINGLÊS vs. inglês-PORTUGUÊS e francês-INGLÊS vs. inglês-FRANCÊS. A Tabela 05 traz os resultados do teste.

Tabela 05: Comparações estatísticas dos TR (ms) entre os pareamentos PGFFR

\begin{tabular}{c|c|c|c}
\hline Combinações com PGFFR & Média $(\mathrm{ms})$ & Valor de T ou Z & Valor de $\boldsymbol{p}$ \\
\hline português- PORTUGUÊS & 1016,55 & $-3,203$ & 0,03 \\
\hline francês- FRANCÊS & 1220,33 & & 0,02 \\
\hline português- PORTUGUÊS & 1016,55 & $-2,673$ & 0,02 \\
\hline inglês- INGLÊS & 1198,55 & \\
\hline
\end{tabular}


A influência do priming grafo-fônico-fonológico em uma tarefa de decisão lexical em multilíngues falantes de português (L1), inglês (L2) e francês (L3) | 21

\begin{tabular}{|c|c|c|c|}
\hline francês- FRANCÊS & 1220,33 & \multirow{2}{*}{, 278} & \multirow{2}{*}{0,32} \\
\hline inglês- INGLÊS & 1198,55 & & \\
\hline português- FRANCÊS & 1126,94 & \multirow{2}{*}{1,623} & \multirow{2}{*}{0,31} \\
\hline francês- PORTUGUÊS & 1011,55 & & \\
\hline português- INGLÊS & 1176,66 & \multirow{2}{*}{4,100} & \multirow{2}{*}{0,01} \\
\hline inglês- PORTUGUÊS & 958,11 & & \\
\hline francês- INGLÊS & 1089,72 & \multirow{2}{*}{$-2,199$} & \multirow{2}{*}{0,05} \\
\hline inglês- FRANCÊS & 1327,88 & & \\
\hline
\end{tabular}

Fonte: elaborado pelas autoras

Como pode ser observado a partir da Tabela 05, 4 das 6 comparações feitas manifestaram diferenças estatisticamente significativas para os TR, como na comparação feita entre portuguêsPORTUGUÊS vs. francês-FRANCÊS $(\mathrm{t}=-3,203, \mathrm{p}<0,05)$. Além disso, as duas línguas representam, respectivamente, a maior e a menor proficiência dos informantes. Ressalta-se, então, nessa comparação, a diferença significativa nos $\mathrm{TR}$, tendo os participantes respondido aos pares de palavras exclusivamente compostos em língua portuguesa $(1016,55 \mathrm{~ms})$ de forma mais rápida, em comparação aos pares compostos apenas em língua francesa (1126,94 ms).

Na combinação português-PORTUGUÊS vs. inglês-INGLÊS $(t=-2,673, p<0,05)$, também se evidenciou diferença estatisticamente significativa, sendo os pares de palavras nos quais ambos os primes e as palavras-alvos eram intralinguísticos. Nesse arranjo, aparecem as duas línguas nas quais os participantes são considerados mais fluentes, mas a diferença estatística significativa enfatiza que a proficiência em língua materna $(1016,55 \mathrm{~ms})$ provê aos multilíngues um poder de decisão lexical que é superior àquele que eles possuem na sua L2 (1198,55 ms).

A combinação a seguir consiste em um pareamento no qual os informantes são mais competentes linguisticamente, o par português-INGLÊS vs. inglês-PORTUGUÊS. Esta comparação mostrou-se significativa em termos estatísticos $(T=4,100, p<0,05)$, pois se averiguou que os participantes são mais rápidos quando os primes são apresentados em língua inglesa $(958,11$ ms) do que quando os distratores são apresentados em L1 (1176,66 ms). Assim, considerando-se os conhecimentos linguísticos em português e em inglês dos participantes, podemos afirmar que o conhecimento que possuem em sua língua inglesa não interfere de forma significativa na ativação do alvo quando estes são apresentados em português, língua materna dos participantes.

A última combinação com diferença estatisticamente significativa foi o pareamento das línguas estrangeiras francês-INGLÊS vs. inglês-FRANCÊS, $(Z=-2,199, p<0,05)$. Nessa comparação, apurou-se que os participantes foram mais rápidos para realizar a tarefa de decisão quando o francês (1089,72 ms) era apresentado na posição de prime, do que quando a língua inglesa aparecia como prime $(1327,88 \mathrm{~ms})$. Cabe ressaltar que o francês é a língua em que os participantes foram classificados com menor proficiência e, de acordo com os resultados, parece ser a língua estrangeira que menos provoca dificuldades para a ativação do alvo, quando é utilizada na posição de prime.

Nas combinações francês-FRANCÊS vs. inglês-INGLÊS $(T=, 278, p>0,05)$ e portuguêsFRANCÊS vs. francês-PORTUGUÊS $(T=1,623, p>0,05)$ não foram encontradas diferenças estatisticamente significativas. Nesse sentido, tem-se as duas línguas estrangeiras dos participantes sendo confrontadas, além da comparação envolvendo a língua materna dos participantes, com a língua estrangeira em que possuem menos proficiência, o francês.

No que diz respeito aos dados relacionados à condição PGFFNR, a Tabela 06 retrata os valores encontrados para a estatística descritiva, para avaliação das médias. 
Tabela 06: Resultados para o TR (ms) na condição PGFFNR

\begin{tabular}{c|c|c}
\hline Combinações PGFFNR & Média $(\mathrm{ms})$ & Medianas $(\mathrm{ms})$ \\
\hline português - PORTUGUÊS & 970,61 & 1003,00 \\
\hline português - FRANCÊS & 1117,11 & 1096,00 \\
\hline português - INGLÊS & 1039,77 & 1018,00 \\
\hline francês - FRANCÊS & 1074,88 & 989,00 \\
\hline francês - INGLÊS & 1012,88 & 1019,00 \\
\hline francês - PORTUGUÊS & 930,66 & 912,00 \\
\hline inglês - INGLÊS & 1089,16 & 995,50 \\
\hline inglês - FRANCÊS & 1155,16 & 1132,50 \\
\hline inglês - PORTUGUÊS & 904,00 & 818,50 \\
\hline
\end{tabular}

Fonte: Elaborados pelas autoras

Ao analisar os TR nas combinações em que a L1 era a palavra-alvo, constou-se que nesses casos os participantes demonstraram maior facilidade em identificar a língua na qual possuem maior proficiência. Assim, a combinação português-PORTUGUÊS registrou média de 970,61 ms $(\mathrm{MD}=1003,00 \mathrm{~ms})$. No arranjo francês-PORTUGUÊS, os sujeitos da pesquisa atingiram média de TR de 930,66 ms (MD = 912,00 ms). A média de TR mais baixa foi apurada na combinação inglêsPORTUGUÊS, que registrou 904,00 ms (MD = 818,50 ms).

Dentre as combinações, o maior TR apresentado foi em inglês-FRANCÊS, tendo registrado média de TR 1155,16 ms ( $M D=1132,50 \mathrm{~ms})$. A combinação francês-INGLÊS cronometrou $1012,88 \mathrm{~ms}(\mathrm{MD}=1019,00)$. As combinações inglês-INGLÊS e português-INGLÊS apresentaram pequenas variações de resultados em seus TR, respectivamente, 1089,16 ms (MD = 995,50 ms) e 1039,77 ms ( $\mathrm{MD}=1018,00 \mathrm{~ms})$. A combinação português-FRANCÊS pode ser identificada com uma das maiores médias de TR, registrando 1117,11 ms $(M D=1096,00 \mathrm{~ms})$. A combinação francês-FRANCÊS evidenciou 1074,88 ms como valor de seu TR (MD = 989,00 ms).

O tratamento estatístico inferencial atribuído aos dados das combinações de PGFFNR foi o mesmo conferido às combinações na condição de PGFFR. Foram comparadas as seguintes combinações entre línguas: português-PORTUGUES vs. francês-FRANCÊS, portuguêsPORTUGUES vs. inglês-INGLÊS, francês-FRANCÊS vs. inglês-INGLÊS, português-FRANCÊS vs. francês-PORTUGUÊS, português-INGLÊS vs. inglês-PORTUGUÊS e francês-INGLÊS vs. inglêsFRANCÊS. A Tabela 07 traz as especificidades que serão detalhadas.

Tabela 07: Comparações estatísticas dos TR (ms) entre os pareamentos PGFFNR

\begin{tabular}{|c|c|c|c|}
\hline Combinações PGFFNR & Média (ms) & Valor de $\mathrm{T}$ ou Z & Valor de $p$ \\
\hline português- PORTUGUES & 970,61 & \multirow{2}{*}{$-1,718$} & \multirow{2}{*}{0,13} \\
\hline francês- FRANCÊS & 1074,88 & & \\
\hline português- PORTUGUÊS & 970,61 & \multirow{2}{*}{$-1,982$} & \multirow{2}{*}{0,48} \\
\hline inglês-INGLÊS & 1089,16 & & \\
\hline francês- FRANCÊS & 1074,88 & \multirow{2}{*}{,-327} & \multirow{2}{*}{, 744} \\
\hline inglês-INGLÊS & 1089,16 & & \\
\hline português- FRANCÊS & 1117,11 & \multirow{2}{*}{$-2,343$} & \multirow{2}{*}{0,19} \\
\hline francês- PORTUGUÊS & 930,66 & & \\
\hline português- INGLÊS & 1039,77 & \multirow{2}{*}{$-1,894$} & \multirow{2}{*}{0,58} \\
\hline inglês- PORTUGUÊS & 904,00 & & \\
\hline francês-INGLÊS & 1012,88 & \multirow{2}{*}{$-2,293$} & \multirow{2}{*}{0,35} \\
\hline inglês-FRANCÊS & 1155,16 & & \\
\hline
\end{tabular}

Fonte: Elaborados pelas autoras 
Como pode ser observado a partir da Tabela 07, nenhuma das 6 combinações feitas entre as línguas estudadas revelou resultados estatisticamente significativos. Isso pode ser interpretado como corroborando o fato de que as supostas semelhanças grafo-fônico-fonológicas afetam a maneira como o acesso lexical é processado em bilíngues e multilíngues, de modo a acarretar maiores TR e diferenças estatisticamente significativas. Os resultados da análise estatística, são os seguintes: português-PORTUGUÊS vs. francês-FRANCÊS, $(\mathrm{T}=-1,718, \mathrm{p}>0,05)$; portuguêsFRANCÊS vs. francês-PORTUGUÊS, $(Z=-2,343, p>0,05)$; combinação entre as línguas estrangeiras, francês-INGLÊS vs. inglês-FRANCÊS $(T=-2,293, p$ >0,05); português-PORTUGUÊS vs. inglês-INGLÊS, $(Z=-1,982, p>0,05)$; português-INGLÊS vs. inglês-PORTUGUÊS, $(Z=$. 1,894, $\mathrm{p}>0,05)$; francês-FRANCÊS vs. inglês-INGLÊS, $(Z=-, 327, \mathrm{p}>0,05)$.

Ao relacionar os resultados encontrados com as teorias que serviram de aporte para o desenvolvimento desta pesquisa, entendemos que há subsídios para acreditar que as supostas semelhanças entres os padrões grafo-fônico-fonológicos entre as línguas. Fazemos menção ao MCU, proposto por MacWhinney (2005), porque acreditarmos que os padrões grafo-fônicofonológicos atuaram como "pistas" linguísticas, culminando na competição entre os itens lexicais ativados. Assim, quando idealizamos a tarefa de decisão lexical, a partir do efeito de priming grafofônico-fonológico, acreditávamos que seriam aguçadas as ativações de mais de um candidato ao uso. Conforme descreve MacWhinney (2005), o concorrente mais favorecido seria o competidor mais forte. No âmbito desta pesquisa, podemos conceber que os candidatos mais fortes tratavam-se dos itens lexicais pertencentes à(s) língua(s) na(s) qual(is) os participantes possuíam maior(es) grau(s) de proficiência, a língua portuguesa e a língua inglesa. Portanto, consideramos que esta concepção indicada por MacWhinney (2005) pode contribuir para esclarecer o motivo de a condição PGFFNR revelar menor TR, em todas as 9 combinações estipuladas nesse trabalho.

Ademais, consideramos que nas combinações intralinguísticas presentes no experimentos de priming, os níveis de proficiência nas línguas exerceram algum tipo de influência na ativação dos padrões grafo-fônico-fonológico supostamente semelhantes entre as línguas. Averiguamos que, ao utilizar línguas nas quais os sujeitos eram mais proficientes na posição de prime, foi possível notar que os TR foram maiores. Esse foi o caso das combinações português-FRANCÊS (em comparação à francês-PORTUGUÊS), português-INGLÊS (em comparação à inglês-PORTUGUÊS) e inglêsFRANCÊS (em comparação à francês-INGLÊS).

Por fim, faz-se importante destacar que os resultados observados nesta pesquisa corroboram os achados de trabalhos como o de Blank (2013), quando a autora aponta os TR necessários para a identificação das palavras-alvo precedidas por primes grafo-fônico-fonológicos foi maior do que quando não havia semelhança entre distrator e alvo Ainda, pode-se fazer uma relação com os resultados encontrados por Toassi (2016) no que tange ao acesso lexical não-seletivo. Nos estudos desenvolvidos por Barcelos (2016) e Pickbrenner (2017) também foram evidenciados resultados que nos levam a creditar na hipótese de seleção não-específica no que diz respeito ao acesso lexical em bilíngues e multilíngues.

\section{Considerações Finais}

No presente estudo, procurou-se contribuir para a compreensão do fenômeno multilíngue no que concerne o acesso lexical. Para isso, investigaram-se os efeitos de priming grafo-fônicofonológico em falantes de português (L1), inglês (L2) e francês (L3), durante uma tarefa de decisão lexical. Ao verificar os resultados obtidos através dos testes de análise estatística, observou-se que, quando deparados com o priming grafo-fônico-fonológico relacionado, os multilíngues revelaram TR maiores para atribuir resposta à palavra-alvo, em comparação aos pares com priming grafofônico-fonológico não relacionado. Comprovou-se a diferença estatisticamente significativa na comparação de TR das condições PGFFR e PGFFNR ( $p<0,05)$, confirmando a noção de que 
quando há semelhanças entre os itens lexicais, ocorre uma maior demanda de processamento, constatada no TR mais elevado. Pode-se atribuir este resultado às transferências grafo-fônicofonológicas (BLANK, 2013) e às relações de níveis de proficiência relatados por Woutersen (1997 apud DE BOT 2007, p. 43).

As línguas em que os participantes possuíam maior nível de proficiência parecem ter causado maiores dificuldades durante o acesso lexical, fazendo que com os TR fossem maiores na condição PGFFR (HERMANS et al., 1998; LEMHÖFER et al., 2004; BLANK; ZIMMER, 2010). Associada a esta conclusão está a Hipótese de Seleção Não-Específica (HSNE) entre as línguas, segundo a qual, com forças diferentes, todas as línguas faladas pelo indivíduo são ativadas, não apenas a língua de resposta (HERMANS et al., 1998; LEMHÖFER et al., 2004). Ainda podem ser vinculadas as influências grafo-fônico-fonológicas que foram depreendidas através da análise estatística às competições travadas entre as línguas (MACWHINNEY, 2005) faladas pelos multilíngues participantes desta pesquisa.

Por fim, acredita-se que os resultados encontrados nesta pesquisa são pertinentes e podem, dadas as devidas proporções, apresentar resultados relevantes ao campo de investigação da Psicolinguística, no que se refere ao acesso lexical em multilíngues, através dos efeitos de priming grafo-fônico-fonológico. Destaca-se, ainda, que são necessários muito mais esforços, no que diz respeito à investigação do fenômeno multilíngue, especialmente se forem consideradas as cerca de 210 línguas faladas no Brasil (OLIVEIRA, 2008). Julga-se haver um campo inexplorado, quanto às inúmeras combinações de línguas que podem ser investigadas.

No que se refere às limitações encontradas no desenvolvimento desse trabalho, precisamos ressaltar que contamos com um número bastante limitado de participantes. Com uma maior amostra populacional de multilíngues, possivelmente, pudessem ter sido traçadas conclusões mais confiáveis. Apesar de termos identificado um número maior de sujeitos que satisfaziam os requisitos estabelecidos, em muitos casos, o número de etapas estipuladas para a seleção de participantes acarretou no não interesse em fazer parte do estudo. Outro fator que contribuiu para a exclusão de alguns candidatos foi o não cumprimento de todo os requisitos instituídos como, por exemplo, não atingimento das proficiências de nível avançado em inglês (L2) e de nível intermediário em francês (L3).

\section{Referências}

BARCELOS, L. O acesso lexical em trilingues brasileiros falantes de português, inglês e francês. Dissertação (Mestrado). Porto Alegre: Universidade Federal do Rio Grande do Sul, 2016.

BLANK, C. A influência grafo-fônico-fonológica na produção oral e no processamento de priming em multilingues: uma perspectiva dinâmica. Tese (Doutorado). Pelotas: Universidade Católica de Pelotas, 2013.

BLANK, C. A transferência grafo-fônico-fonológica L2 (francês) - L3 (inglês): um estudo conexionista. Dissertação (Mestrado). Pelotas: Universidade Católica de Pelotas, 2008.

BLANK, C.; ZIMMER, M. C. A transferência fonético-fonológica L2 (francês) - L3 (inglês): um estudo de caso. Revista de Estudos da Linguagem, v. 17, pp. 207-233, 2010.

BRITO, K. Influências interlinguísticas na mente multilíngue: perspectivas psicolinguísticas e (psico) tipológicas. Tese (Doutorado). Curitiba: Universidade Federal do Paraná, 2011.

BROWN. Corpus da lingua inglesa. Disponível em: <http://www.hit.uib.no/icame/brown/bcm.html>. Acesso em: 03 Jan 2017.

BUSNELLO, R. Efeito de priming subliminar no acesso ao léxico. Dissertação (Mestrado). Porto Alegre: PUCRS, 2006. 
A influência do priming grafo-fônico-fonológico em uma tarefa de decisão lexical em multilíngues falantes de português (L1), inglês (L2) e francês (L3) | 25

CETEN-FOLHA. Corpus da lingua portuguesa. Disponível em: <http://www.linguateca.pt/>. Acesso em: 03 Jan 2017.

CONKLIN, K.; MAUNER, G. Investigating Bilingual Lexical Access: Processing French-English Homographs in Sentential Contexts. Proceedings of the $4^{\text {th }}$ International Symposium on Bilingualism. Arizona, April, pp. 552-569, 2005.

DE BOT, K.; LOWIE, W.; VERSPOOR, M. A dynamic systems theory approach to second language acquisition. Bilingualism: Language and Cognition, n.10, v.1, pp.7-21, 2007.

DUARTE, A. Priming grafo-fônico-fonológico em multilíngues: Uma abordagem dinâmica. Dissertação (Mestrado). Pelotas: Universidade Federal de Pelotas, 2018.

E-PRIME 2.0. Released 2012. (Psychology Software Tools, Inc.), <https://pstnet.com/e-primepublications/>, 2012.

FRANÇA, A.; LEMLE, M.; GESUALDI, A.; CAGY, M.; INFANTOSI, A. A neurofisiologia do acesso lexical: Palavras em português. Veredas (UFJF), v. 2, pp. 34-49, 2008.

HERMANS, D.; BONGAERTS, T.; DE BOT, K.; SCHREUDER, R. Producing words in a foreign language: can speakers prevent interference from their first language? Bilingualism: Language and Cognition, 1, pp. 213-230, 1998.

IBM CORP. Released 2013. IBM SPSS Statistics for Windows. New York: IBM Corp, 2013.

LEMHÖFER, K.; DIJKSTRA. T.; MICHEL, M. Three languages, one ECHO: Cognate effects in trilingual word recognition. Language and Cognitive Processes, 19(5), pp. 585-611, 2004.

LEXIQUE. Corpus da lingua francesa. Disponível em: <http://www.lexique.org/>. Acesso em: 03 Jan 2017.

LIMBERGER, B. K. Processamento da leitura multilingue e suas bases neurais: um estudo sobre o Hunsriqueano. Tese (Doutorado). Porto Alegre: Pontifícia Universidade Católica do Rio Grande do Sul, 2018.

MACWHINNEY, B. Extending the competition model. International Journal of Bilingualism, 9, pp. 69-84, 2005.

OLIVEIRA, Gilvan M. Plurilinguíssimo no Brasil. Brasilia: Representação da UNESCO no Brasil / IPOL, 2008. Disponível em: 〈http://unesdoc.unesco.org/images/0016/001611/161167por.pdf>. Acesso em: 10 ago 2019.

PICKBRENNER, M. O acesso lexical em multilingues inglês (L2) e alemão (L3) no reconhecimento de palauras tipologicamente similares. Tese (Doutorado). Porto Alegre: Universidade Federal do Rio Grande do Sul, 2017.

RODRIGUEZ-FORNELLS, A.; VAN DER LUGT, A.; ROTTE, M.; BRITTI, B.; HEINZE, H.; MUNTE, T. Second language interferes with word production in fluent bilinguals: rain potential and functional imaging evidence. Journal of Cognitive Neuroscience, v. 17, pp. 422-433, 2005.

TOASSI, P. F. P. Investigating lexical access in multilinguals: a study on the processing of English as L3. Tese (Doutorado). Florianópolis: Universidade Federal de Santa Catarina, 2016.

TOASSI, P. F. P; MOTA, M., B. Acesso lexical de bilíngues e multilíngues. Acta Scientiarum. Language and Culture (Online), v. 37, pp. 393-404, 2015.

Recebido em: 17/09/19

Aceito em: 03/11/19 